(REVIEW ARTICLE)

\title{
Soft skills and its application in work place
}

\section{S. Vasanthakumari}

Associate Professor, School of Nursing and Midwifery, Institute of Health Sciences, Wollega University, Nekemte, Ethiopia.

Publication history: Received on 30 August 2019; revised on 23 September 2019; accepted on 26 September 2019

Article DOI: https://doi.org/10.30574/wjarr.2019.3.2.0057

\begin{abstract}
Soft skills refer to a cluster of personal qualities, habits, attitudes and social graces that make someone a good employee and compatible to work with. There are two types of skills viz hard and soft skill. Soft skills are important for professional development, maintaining IPR and effective Communication. Soft skills include Inter personal and Personal attributes that enhance an individual's interactions, job performance and career prospects. There are many key soft skills that need to be applied in work place. Hence Soft skills training should begin for a person when they are students, to perform efficiently in their academic environment as well as in their future workplace.
\end{abstract}

Keywords: Soft skill; Hard skill; IPR; Communication; Soft skill training

\section{Introduction}

It's often said that hard skills will get you an interview but you need soft skills to get -- and keep -- the job. What makes one stand out from others???

Good Soft Skills....Will help you STAND OUT in a crowd of mediocrity.

Soft skills are a synonym for 'Peoples Skills', 'Interpersonal Skills' and also 'Transferable Skills” .Soft skills are Personal attributes that enhance an individual's interactions, job performance and career prospects. In other words they are the subtle behaviours and communication styles that help make a work environment or interaction with another person easier to manage. [1-7].

\section{Literature review on significance of soft skills in work place}

Studies by Stanford Research Institute and the Carnegie Mellon Foundation among Fortune 500 CEOs established that $75 \%$ of long term job success resulted from soft skills mastery and only $25 \%$ from technical skills. [7].

Researchers at Boston University, University of Michigan's Ross School of Business found that workers with soft skills training are $12 \%$ more productive than those without them. [7].

Harvard University reported that $85 \%$ of success at the work place is attributed to Soft skills and only $15 \%$ to technical skills. [6].

A public interest study conducted by McDonald's in UK predicted over half a million people will be held back from job sectors by 2020 due to lack of soft skills.[7].

\footnotetext{
${ }^{*}$ Corresponding author

E-mail address: vasanhar@yahoo.com
} 


\section{Types of soft skills in work place}

Hard skills are the technical skills individual use each day to perform the job. Some examples would be computer skills or procedural knowledge applied in job. $[3,4,6]$.

Unlike hard skills, which can be proven and measured, Soft skills are intangible and difficult to quantify and they help facilitate human connections. Hard skills, tend to be specific to a certain type of task, soft skills are broadly applicable. $[3,4,6]$.

\section{Soft skills: defined}

Soft skills refer to a cluster of personal qualities, habits, attitudes and social graces that make someone a good employee and compatible to work with According to Collins English Dictionary term "soft skills" defined as "desirable qualities for certain forms of employment that do not depend on acquired knowledge: they include common sense, the ability to deal with people, and a positive flexible attitude." $[5,6]$.

\section{Why do soft skills matter?}

Soft skills are a combination of people skills, social skills, communication skills, character or personality traits, attitudes, career attributes, social and emotional intelligence, intelligence quotients, that enable people to navigate their environment, work well with others, perform well, and achieve their goals with complementing hard skills. [7, 8].

Soft skills differentiate between adequate candidates and ideal candidates. [7, 8].

In most competitive job markets, recruitment criteria do not stop at technical ability and specialist knowledge. Recruiters will be looking for people who can become leaders, and leadership, itself, depends on several key soft skills. $[6,7,8]$.

Soft skills acts as key in building relationships, gaining visibility, and creating more opportunities for advancement. [7, 8].

\section{Importance of soft skill $[2,5,6]$}

- To handle interpersonal relations

- To take appropriate decisions

- To communicate effectively

- To have good impression and impact to gain professional development

\section{Soft Skills: Examples [6, 7, 8]}

\subsection{Interpersonal attributes}

Empathy, Leadership, Communication, Teamwork, Good manners, Ability to teach, Works well with diversity, Selfconfidence

\subsection{Personal attributes}

Optimism, Responsibility, Sense of humor, Integrity, Time management, Motivation, Common Sense

\section{Key soft skills required $[4,6,7,8]$}

\subsection{Communication skill}

Communication skills form the corner stone of Soft Skill. It is a process through which a message is exchanged from the sender to the receiver and vice versa. 


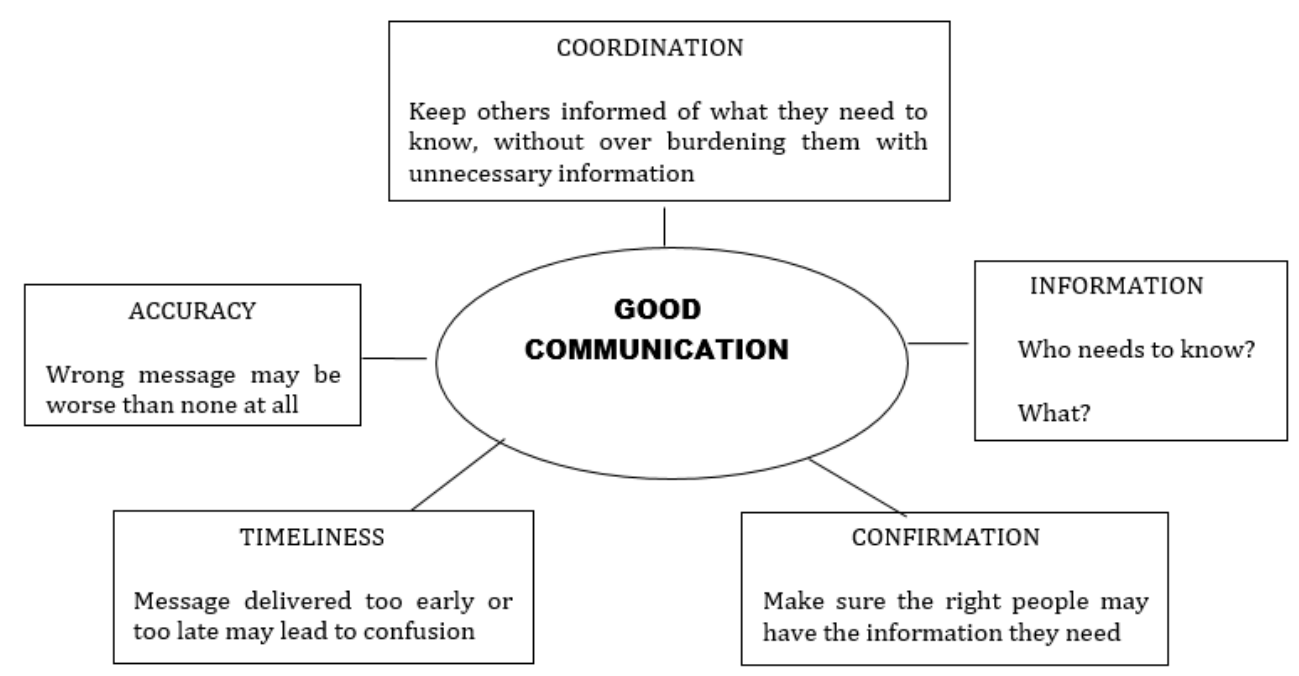

Figure 1 Good Communication

\subsubsection{Verbal communication}

It is essential to communicate appropriately with colleagues, seniors and subordinates to avoid any sort of misunderstanding and misinterpretation at the workplace.

Language

It is a tool which is used to communicate a message from one to one another of the same group. It is also called as verbal communication.

Important facts about language

The grammar has to be properly used to during all the conversations.

Always think before you talk

Use simple and short sentences to convey your messages.

Avoid using complex and long sentences.

Don't use verbal and nonverbal fillers during the conversation.

Grammar

It is a set of guidelines which tells us clearly how, when and where to use the words of any given language.

The rate of speech

To communicate clearly, a rate of speech plays a vital role. An average rate of speed should be maintained to deliver the message clearly. The average speed of a perfect speaker is around 130 to 160 words per minute.

\subsubsection{Non-verbal communication}

Body language, also called as a nonverbal communication. It presents to the audience what we feel \& think about the particular matter.

Body language

It is a natural representation which is inbuilt within each and every living organism in this world. It is also known as the first language of the world. 


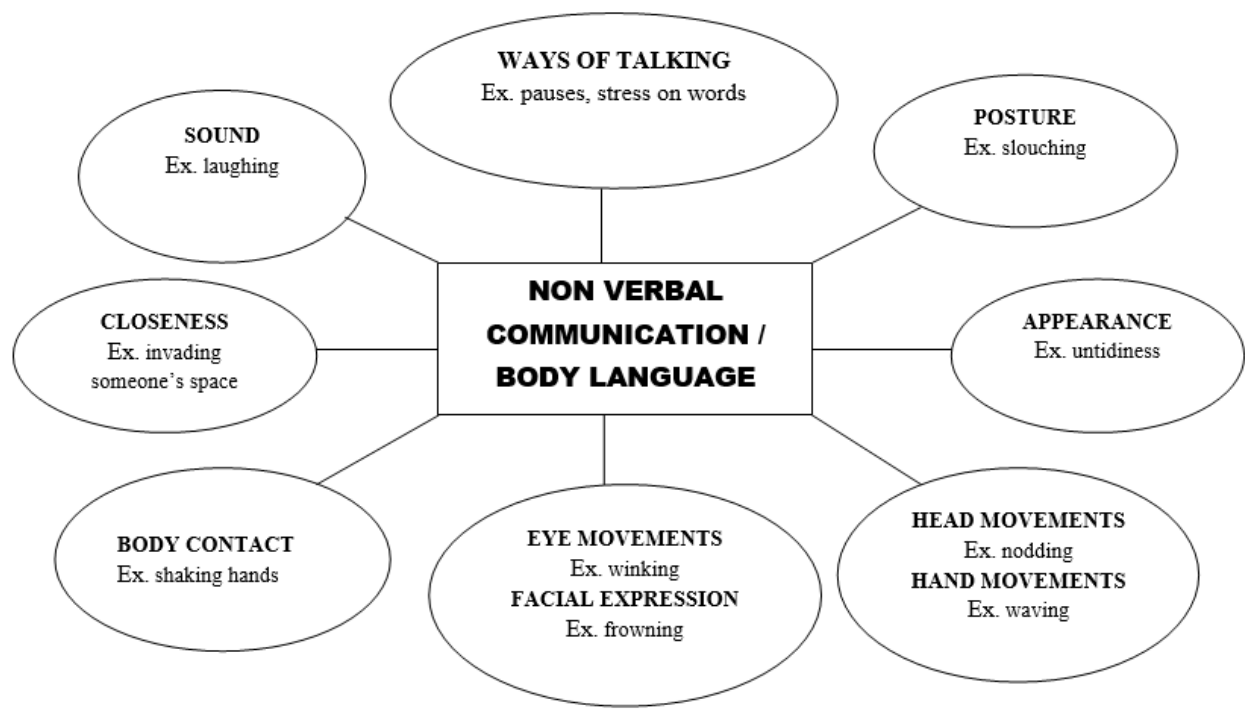

Figure 2 Non Verbal Communication

\subsubsection{Written Communication Skill}

Writing evaluates a person's proficiency indications, spelling, grammar etc.

\subsubsection{Presentation skills}

Include planning, preparation \& delivery of the message. Making a formal speech is one form of presentation. Presentation skills can be broadly categorized into physical, oral, \& electronic.

\subsection{Team work}

It is the collaborative effort of a team to achieve a common goal or to complete a task in the most effective and efficient way. People of either gender, different age groups, qualification, status \& skills work as a team with a common objective of accomplishing the task.

\subsection{Professional ethics}

It is defined as the personal and corporate rules that govern behaviour within the context of a particular profession.

\subsection{Interpersonal skills}

It is the ability to communicate or interact well with other people. Man is a social animal \& his success in life largely depends on his relationship \& interaction with others.

\subsection{Interpersonal skills and Personal chemistry}

Interpersonal Defined: of or pertaining to the relations between persons, Personal Chemistry: In the context of relationships, it is a simple "emotion" that people get when they share a special connection. It is important in Interpersonal relationship to decide who will be with each other.

\subsection{Time management and how to work under pressure}

"Time management" is the process of organizing and planning how to divide your time between specific activities. Good time management enables you to work smarter - not harder - so that you get more done in less time, even when time is tight and pressures are high. Failing to manage time damages the effectiveness and causes stress.

\subsection{Leadership}

Leadership is the ability to influence others, with or without authority. All successful endeavors are the result of human effort; thus, the ability to influence others is a derivation of Interpersonal Communications, Conflict Management, Problem Solving / Decision Making. 


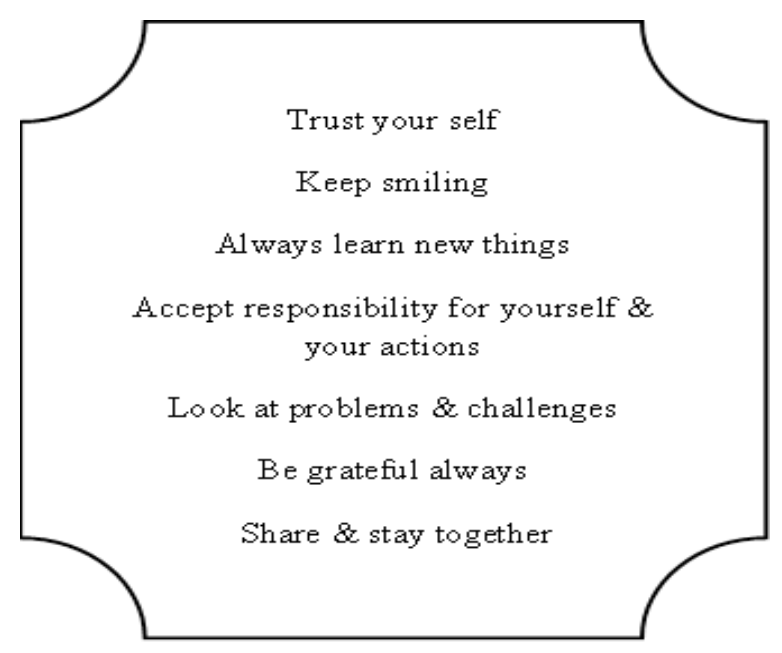

Figure 3 Leadership Skills

\subsection{Critical thinking}

Critical thinking is the ability to think clearly and rationally, understanding the logical connection between ideas.

\subsection{Problem solving}

Problem solving is the act of defining a problem, determining the cause of the problem, identifying, prioritizing and selecting alternatives for a solution, and implementing a solution.

\subsection{Creativity}

It is defined as the tendency to generate or recognize ideas, alternatives, or possibilities that may be useful in solving problems, communicating with others, and entertaining ourselves and others.

\subsection{Conflict resolution}

It is conceptualized as the methods and processes involved in facilitating the peaceful ending of conflict and retribution.

\subsection{Negotiation}

It is a method by which people settle differences. It is a process by which compromise or agreement is reached while avoiding argument and dispute.

\subsection{Decision making}

It is the cognitive process resulting in the selection of a belief or a course of action among several alternative possibilities.

\subsection{Self-motivation}

It is the ability to do what needs to be done, without influence from other people or situations.

\subsection{Self confidence}

It is self-assurance in one's personal judgment, ability, power etc.

\subsection{Self awareness}

It is the capacity for introspection and the ability to recognize oneself as an individual separate from the environment and other individuals. 


\section{Soft skills used in work place $[2,5,6,7]$}

- Communication skills, Body language

- Team skills

- Ways to manage time

- Stress Management strategies - Changing one's Focus (diversional activities)

- Leadership strategies

- Critical thinking - Now a day's no need to think there is a box but simply realize there is no box

- Showing kindness and courtesy

- Being Flexible and Adaptable

- Maintaining Eye contact, Using common sense

- Intelligence quotient (IQ)

- EI-Emotional intelligence

- Positive work ethics and attitude

- Maintaining good personal appearance

- Understanding what the world is about (what's going on in the news?)

- Willingness to take instruction and responsibility

- Able to relate to co-workers in a close environment

- Not expecting to be promoted within the first six month

- Membership and Volunteering

\section{Good basic life lesson to be learnt to be successful at work place $[6,7,8]$}

- You are responsible for yourself

- Don't be afraid of something. Learn about it!

- Skill and Technical competency is the core of your career!

- What you don't know may hurt you, or hold you back

- Develop important soft skills

- Build on your strengths; target weaknesses

- What you don't know may hurt you, or hold you back

- Don't be afraid of something. Learn about it!

- Build on your strengths ; target weaknesses

- Develop important soft skills

- Skill and Technical competency is the core of your career!

- The Choice is yours

- With a Bad attitude you can never have a positive day

- With a Positive Attitude you can never have a bad day

\section{Preparation of a resume and self-introduction: $[7,8,9]$}

- Push the soft skills during self introduction, in resume and during job interview

- High light the Soft skill while describing yourself, narrating work history/ experience

- In curriculum vitae, mention one or two of the skills, and give specific examples of instances when you demonstrated these traits at work.

- When you attend an interview, remember that this is your first chance to show your interpersonal skills to your prospective employers.

- Be professional, make eye contact, shake hands, listen closely to the questions and answer them fully. 


\section{How to improve your soft skills $[1,9]$}

- Take online courses

- Get feedback from others

- $\quad$ Practice with a friend

- Get a coach

\section{Conclusion}

Hard skills help to acquire employment and Soft skills helps to ensure the employability. Hence it is essential to integrate hard skills with soft skills to fast track the career. Soft skill is an umbrella term for skills under three key functional elements: people skills, social skills, and personal career attributes. Experts say soft skills training should begin for a person when they are students, to perform efficiently in their academic environment as well as in their future workplace. $[1,2,6]$

Pick one skill...work on it....Practice!

\section{Compliance with ethical standards}

\section{Acknowledgments}

I would like to acknowledge Wollega University and my Pediatric Nursing Department Heads Mr. Werku Etafa M.Sc(N) and Mr. Bizuneh Wakuma M.Sc(N), Dean Mr. Eba Abdissa M.Sc(N), Head of Department (Nursing) Tadele Amente Belisa M.Sc(N), Research Technology Transfer Post Graduate Coordinator Mr. Motumma MPH(RH).

\section{Disclosure of conflict of interest}

Author declare that there are no conflicts of interest in any form.

\section{References}

[1] Silber H, Kenneth and Foshay RW. (2009). Handbook of Improving Performance in the Workplace, Instructional Design and Training Delivery, John Wiley \& Sons, New York, 63.

[2] Anju A. (2009). A Holistic Approach to Soft Skills Training. IUP Journal of Soft Skills, 3(1), 7-11.

[3] Dennis R Laker and Jimmy LP. (2011). The differences between hard and soft skills and their relative impact on training transfer. Human Resource Development Quarterly, 22(1), 111-122.

[4] Jane A and Helen H. (2008). Graduate Employability, 'Soft Skills' Versus 'Hard Skills' Business Knowledge: A European Study, Journal of Higher Education in Europe, 33(4), 412- 422.

[5] Jungsun K, Mehmet E, JeoungWoo B and Hwayoung J. (2011). Training soft skills via e-learning, International Journal of Contemporary Hospitality Management, 23(6), 739-763.

[6] www.workforce.com

[7] https://www.thebalancecareers.com/list-of-soft-skills-2063770

[8] https://www.thebalancecareers.com/what-are-soft-skills-2060852

[9] https://www.wikijob.co.uk/content/interview-advice/competencies/soft-skills

\section{How to cite this article}

S. Vasanthakumari. (2019). Soft skills and its application in work place. World Journal of Advanced Research and Reviews, 3(2), 66-72. 